\title{
Synthesis of Submicrometer Calcium Carbonate Particles from Inorganic Salts Using Linear Polymers as Crystallization Modifiers
}

\author{
Sara E. Facchinetto, Tanize Bortolotto, Gabrielly E. Neumann, Jean C. B. Vieira, \\ Bryan B. de Menezes, Cristiano Giacomelli and Vanessa Schmidt*
}

\author{
${ }^{a}$ Departamento de Química, Universidade Federal de Santa Maria, 97105-900 Santa Maria-RS, Brazil
}

\begin{abstract}
In this study, we report the synthesis of submicrometer calcium carbonate particles using the simplest approach of mixing solutions of calcium chloride and ammonium carbonate inorganic precursors in the presence of crystallization modifiers. Instead of the typical crystallization of $\mathrm{CaCO}_{3}$ into large calcite crystals with rhombohedral morphology, very small uniform spherical vaterite particles were formed with the addition of small amounts of the anionic homopolymer poly(sodium 4-styrenesulfonate) (PSS). In contrast, large spheres made of a collection of calcite polycrystallite aggregates formed in the presence of poly(acrylic acid) (PAA). Crystal growth in a pre-organized environment created by the selective distribution of $\mathrm{Ca}^{\mathrm{II}}$ ions in the shell of polyestyrene- $b$-poly(acrylic acid) (PS- $b$-PAA) core-shell spherical micelles revealed a rather poor control of the size and morphology. Therefore, the PSS anionic homopolymer can be applied to the synthesis of submicrometer $\mathrm{CaCO}_{3}$ particles from solutions of inorganic salts, which is a much cheaper and sustainable method than controlled $\mathrm{CO}_{2}$ gas production and diffusion.
\end{abstract}

Keywords: nanocomposites, polycaprolactone, calcium carbonate particles, crystallization modifiers

\section{Introduction}

One of the most important advances in materials science and engineering is the possibility of reinforcing polymers with cost-effective fillers such as carbon black, clays, silicates and limestone (calcium carbonate). Fillers are added to formulations in order to fine tune the physical and mechanical properties, or simply to reduce the cost of production by decreasing the amount of polymer resin. ${ }^{1}$

Although calcium carbonate is an abundant naturally occurring mineral already largely used in the polymer industry, recently the clever manipulation of particle size and its effects on the material properties has attracted considerable attention. ${ }^{2-12}$

Nano- and micrometer calcium carbonate particles can be synthesized by a variety of methods, including controlled gas diffusion, colloidal/microemulsion systems, sonochemistry, hydrothermal synthesis, etc. The simplest approach consists of the precipitation of calcium carbonate from solutions containing inorganic salts as a source of calcium(II) and carbonate ions. In this case, the precipitation of calcium carbonate involves a complex set

*e-mail: vschmidt@ufsm.br of processes of crystal nucleation and growth that is very sensitive to the chemical environment. ${ }^{5}$ The diverse atomic arrangements found in calcium carbonate materials (three crystalline polymorphs: calcite, vaterite, and aragonite; two hydrated metastable forms: monohydroxycalcite and calcium carbonate hexahydrate; and an unstable amorphous phase) can therefore be controlled by the addition of appropriate crystallization modifiers. These include metallic ions, surfactants, ${ }^{10,13}$ biopolymers, ${ }^{2,14-16}$ and synthetic polymers..$^{2-6,9,17-25}$ Indeed, crystallization control is a critical requirement in the synthesis of many important materials.

In this context, it has been demonstrated that synthetic polymers alter the crystallization and they have consequently found extensive application in industry, for instance, as limescale inhibitors in boilers and water pipes. One common feature of polymers able to control the crystallization of calcium carbonate, such as poly(styrene sulfonate) $)^{5,9,23}$ and poly(acrylic acid), 4,17,18,26-28 is that they are anionic (or contain anionic segments) and are therefore capable of interacting with calcium(II) ions and with the crystal surface itself.

The precipitation of calcium carbonate in the presence of polymeric crystallization modifiers differs from the 
conventional ion-by-ion growth. Instead, the crystallization usually begins with the formation of small particles of amorphous calcium carbonate (ACC), which are rapidly converted into more stable structures, particularly into calcite or vaterite primary particles. ${ }^{5,13}$ Through specific interaction with functional groups attached to the polymer, these particles are stabilized, thus retarding further growth. They can therefore aggregate and generate diverse morphologies including hollow spheres, spherules, dumbbells and disks, depending on the experimental conditions.

This article describes, for the first time at the best of our knowledge, the synthesis of submicrometer calcium carbonate particles, using the simplest approach of mixing solutions of calcium chloride and ammonium carbonate inorganic precursors in the presence of crystallization modifiers, and their application in the production of nanocomposites. We show how very small uniform spherical particles can be prepared in the presence of small amounts of the anionic homopolymer poly(sodium 4-styrenesulfonate) (PSS). Under the same experimental conditions, we studied the effects of different polymer structures containing the carboxylic group (linear poly(acrylic acid); PAA), and of a pre-organized environment created by the selective distribution of $\mathrm{Ca}^{\mathrm{II}}$ ions.

The surface-modified submicrometer calcium carbonate particles were then used to produce poly( $\varepsilon$-caprolactone) (PCL) composites. PCL has been attracting solid investment aimed at developing biodegradable polymeric materials..$^{29,30}$ It is well-known that for most applications PCL-based materials require blending with other resins or filling with inorganic particles to further improve the processing and mechanical properties. ${ }^{29-33}$ Oscillatory rheology of PCL/polymer@ $\mathrm{CaCO}_{3}$ composites, where polymer@ $\mathrm{CaCO}_{3}$ refers to $\mathrm{CaCO}_{3}$ nanoparticles coated with a polymer, in the melt state was used to establish the effects of polymer@ $\mathrm{CaCO}_{3}$ particles on the characteristic behavior of PCL.

\section{Experimental}

\section{Materials}

Calcium chloride, calcium nitrate, sodium carbonate, ammonium carbonate, poly(sodium 4-styrenesulfonate) (PSS, weight-average molecular weight $\left.(\mathrm{Mw})=70,000 \mathrm{~g} \mathrm{~mol}^{-1}\right)$ and polyestyrene- $b$ poly (acrylic acid) $\left(\mathrm{PS}_{60}-b-\mathrm{PAA}_{30}, \mathrm{Mw}=8,400 \mathrm{~g} \mathrm{~mol}^{-1}\right)$ were acquired from Sigma-Aldrich Co., and used as received. Poly(acrylic acid) (PAA, Mw $=7,200 \mathrm{~g} \mathrm{~mol}^{-1}$ ) was obtained after hydrolysis of poly(terc-butyl acrylate), which was synthesized by RAFT (reversible addition-fragmentation chain transfer) polymerization following a procedure reported earlier. ${ }^{34}$

\section{Particle synthesis}

\section{Synthesis of polymer@ $\mathrm{CaCO}_{3}$ particles}

In a typical experiment, calcium chloride was added to a previously prepared aqueous solution containing the homopolymer, which was first dissolved in water by direct dissolution. The resulting solutions contained $0.1 \mathrm{~mol} \mathrm{~L}^{-1}$ $\mathrm{CaCl}_{2}$ and the polymer at different concentrations, as specified below. To this solution, $0.1 \mathrm{~mol} \mathrm{~L}^{-1}\left(\mathrm{NH}_{4}\right)_{2} \mathrm{CO}_{3}$ was added dropwise. During this process, the temperature was kept constant at $25{ }^{\circ} \mathrm{C}$ using a jacketed vessel. Immediately after the addition of $\left(\mathrm{NH}_{4}\right)_{2} \mathrm{CO}_{3}$, the resulting solution was centrifuged at 12,000 rpm for $2 \mathrm{~h}$, and the precipitate was washed first with water and then with ethanol. Finally, solid samples were dried in a heated oven at $75{ }^{\circ} \mathrm{C}$ for $24 \mathrm{~h}$. When indicated, the temperature was raised to $80{ }^{\circ} \mathrm{C}$ (heating rate $=5{ }^{\circ} \mathrm{C} \mathrm{min}^{-1}$ ) after the addition of the $\left(\mathrm{NH}_{4}\right)_{2} \mathrm{CO}_{3}$ was completed, and kept constant for $140 \mathrm{~min}$.

\section{Physical methods and techniques}

\section{Fourier transform infrared spectroscopy (FTIR)}

$\mathrm{KBr}$ pellets were prepared using 2-3 $\mathrm{mg}$ of polymer@ $\mathrm{CaCO}_{3}$ particles. Background corrected spectra were recorded using a Bruker Tensor-27 spectrometer with $4 \mathrm{~cm}^{-1}$ of resolution.

\section{Powder X-ray diffraction (XRD)}

XRD data were collected on a Bruker D8 Advance diffractometer with $\mathrm{Cu} \mathrm{K} \alpha$ radiation $(\lambda=1.54184 \AA$ ) using a nickel absorber to filter $K \beta$ radiation with a LYNXEYE $\mathrm{XE} 1-\mathrm{D}$ detector. The measurement range was from $20^{\circ}$ to $60^{\circ} 2 \theta$ angles with a step size of 0.02 degree and an exposure time of $500 \mathrm{~ms}$ per step.

\section{Thermogravimetric analysis (TGA)}

TGA runs were conducted using a TA Instruments Q5000 apparatus at a heating rate of $10^{\circ} \mathrm{C} \mathrm{min}^{-1}$ from room temperature to $700{ }^{\circ} \mathrm{C}$. The nitrogen flow was maintained at $50 \mathrm{~cm}^{3} \mathrm{~min}^{-1}$ during the analysis.

\section{Scanning electron microscopy (SEM)}

The particulate material was deposited on stubs covered with double-sided carbon adhesive tape. The stubs were then tapped gently to remove any excess material not adhered to the tape. Subsequently, particles remaining on 
the stub were gold coated on an ion sputter. SEM images were acquired using a JEOL 55 M6360 microscope at an accelerating voltage of $20 \mathrm{kV}$.

\section{Rheology}

Rheological experiments were carried out on a stresscontrolled rheometer (TA Instruments AR-G2) equipped with an environmental test chamber (ETC). The ETC was fitted with a standard parallel plate geometry accessory kit suitable for thermoplastics and rubbers. The composite material was loaded onto the plate equilibrated at $100{ }^{\circ} \mathrm{C}$ for $15 \mathrm{~min}$. Subsequently, the gap was then closed to $100 \mu \mathrm{m}$ using the exponential sample compression mode. The ETC chamber was then opened, and the excess sample was trimmed using a flat-ended tool while the bearing was locked to prevent rotation. Prior to the experiments, a conditioning step was applied to the sample by setting the temperature at $100{ }^{\circ} \mathrm{C}$ for $15 \mathrm{~min}$ at rest. Initially, a strain amplitude of $5 \%$ was applied in all dynamic tests to ensure that the deformation was within the linear viscoelastic regime. The linear viscoelastic region was determined by a strain sweep from 0.1 to $5 \%$ performed at a frequency of $1 \mathrm{~Hz}$ at $100{ }^{\circ} \mathrm{C}$. Frequency sweeps were run at $100{ }^{\circ} \mathrm{C}$ over an experimental range of 0.06 to $628 \mathrm{rad} \mathrm{s}^{-1}$ and the values for the viscoelastic properties, storage modulus $\left(\mathrm{G}^{\prime}\right)$ and loss modulus (G”) were determined. The polymer molecular structure dictates the magnitude and shape of the G' and G" curves. Steady-state flow experiments were performed within the shear rate range of $0.01-10 \mathrm{~s}^{-1}$.

\section{Results and Discussion}

The presence of PSS molecules in the crystallizing solution promoted a significant change in the morphology of the precipitated calcium carbonate inorganic particles (Figure 1). The SEM image of $\mathrm{CaCO}_{3}$ obtained in the absence of PSS (Figure 1a) revealed the formation of large crystals with rhombohedral morphology, as expected under these experimental conditions. ${ }^{6}$ On the other hand, smaller particles with spherical morphology were obtained when precipitation occurred in the presence of PSS. As the homopolymer concentration increased (Figures $1 \mathrm{~b}$ to $1 \mathrm{~d}$ ), the precipitated particles preserved their morphology, but the size decreased significantly, that is, to the submicrometer range (from ca. 4 down to $0.8 \mu \mathrm{m})$. The uniformity of both the shape and size of the spherical structures is a remarkable feature of such samples, as observed in Figure 1d.
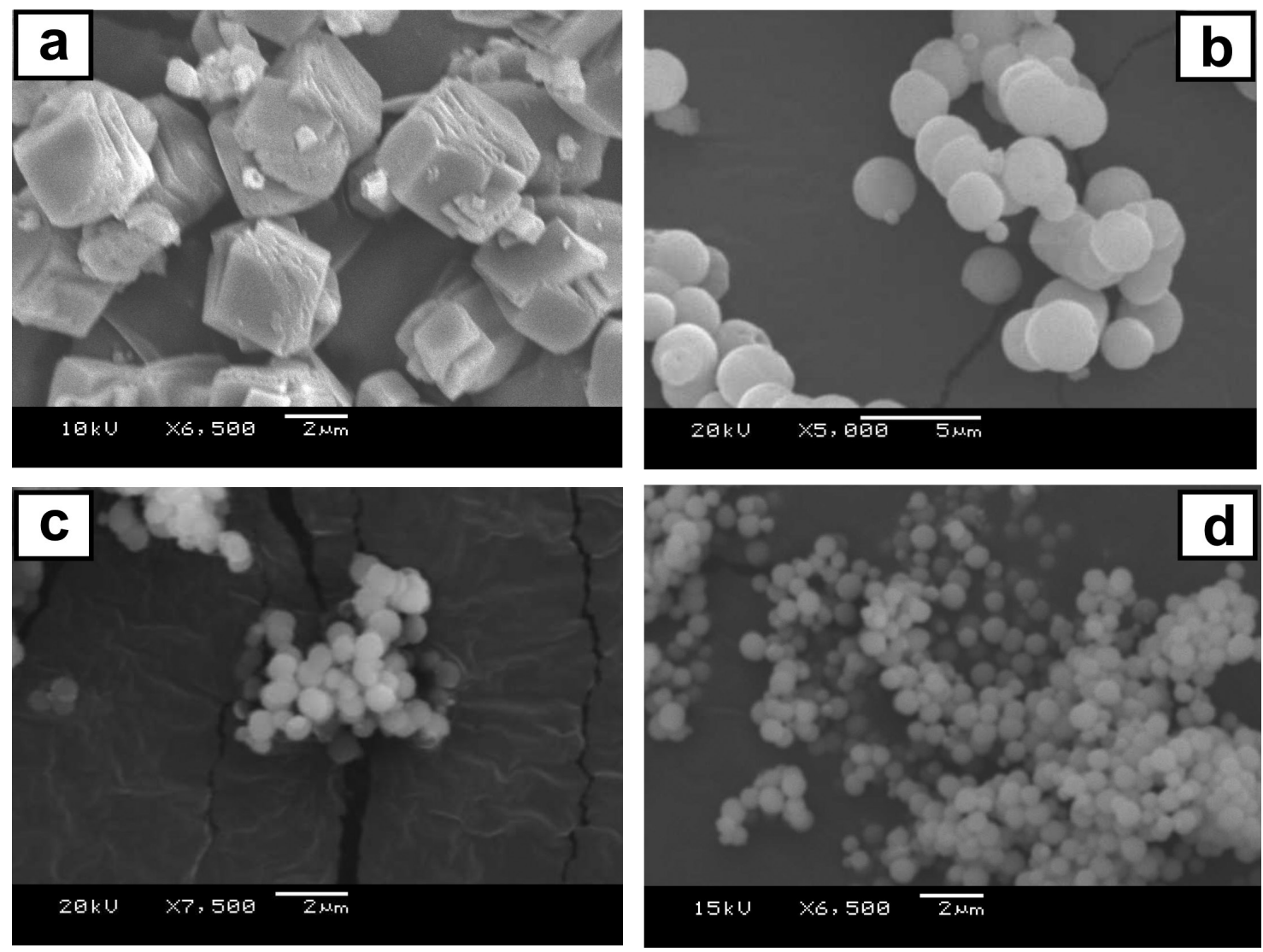

Figure 1. $\mathrm{CaCO}_{3}$ particles precipitated from solutions containing no additive (a), and $\mathrm{PSS} @ \mathrm{CaCO}_{3}$ particles grown in the presence of 0.05 (b), 0.10 (c), and $2.00 \mathrm{mg} \mathrm{mL}^{-1} \mathrm{PSS}$ (d). Experimental conditions: $\left[\mathrm{Ca}^{2+}\right]:\left[\mathrm{CO}_{3}{ }^{2-}\right]=3: 1$. 
To gain an insight into the effect of this anionic polymer on the modulation of the $\mathrm{CaCO}_{3}$ structure, the calcium carbonate crystal structure was determined by FTIR $^{35-37}$ and the results are shown in Figure 2a. The absorption band at $714 \mathrm{~cm}^{-1}$ is characteristic of the most stable rhombohedral polymorph (calcite), and is not observed when $\mathrm{CaCO}_{3}$ was precipitated in the presence of PSS. Instead, the vaterite phase is stabilized under these experimental conditions, as indicated by the absorption band at $745 \mathrm{~cm}^{-1} .36$ Whilst the addition of PSS modified the interaction between developing particles, ${ }^{19,38}$ ultimately leading to changes in the crystal structure of $\mathrm{CaCO}_{3}$ particles from calcite to vaterite, the polymer concentration effects were limited to the particle diameter variations, that is, no structural changes were identified within the polymer concentration range used in this study. These results were corroborated by XRD data shown in Figure 2b. The measured powder patterns were compared with the database Powder Diffraction Files (PDF) from the International Center of Diffraction Data (ICDD). The search results PDF 00-005-0586 and PDF 00-033-0268, corresponding to calcite and vaterite, respectively, match exactly with the expected compositions in each powder pattern.

The formation of spherical vaterite particles at a high [Ca]:[S] ratio (3:1) with $[\mathrm{Ca}]=33 \mathrm{mmol} \mathrm{L}^{-1}$ and high polymer concentration is, in fact, favored over polycrystalline calcite aggregates, as noted previously elsewhere. ${ }^{5}$ However, much to our surprise, the diameter of the vaterite particles was very small. Samples synthesized in this study consisted of ca. 0.8 to $4 \mu \mathrm{m}$ diameter particles, which are much smaller than the 20- $\mu$ m analogs synthesized by Kulak et al. ${ }^{5}$ using poly(ethylene oxide)-b-poly(sodium 4-styrenesulfonate) amphiphilic block copolymers. This characteristic of the particles leads to the specific surface
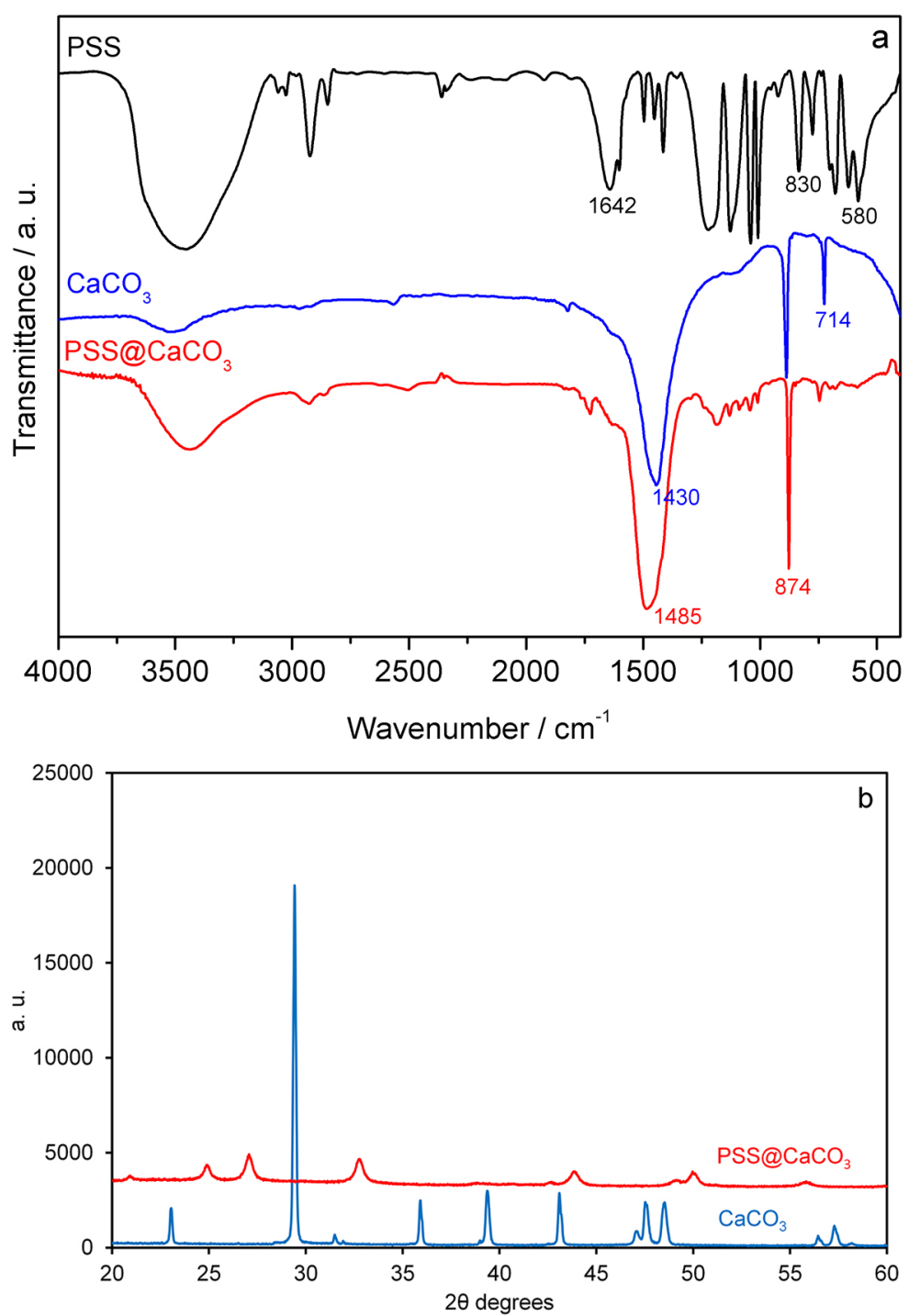

Figure 2. (a) FTIR spectra and (b) XRD patterns for neat PSS polymer and $\mathrm{CaCO}_{3}$ particles precipitated in the absence and in the presence of $2.00 \mathrm{mg} \mathrm{mL}^{-1}$ PSS, as indicated. 

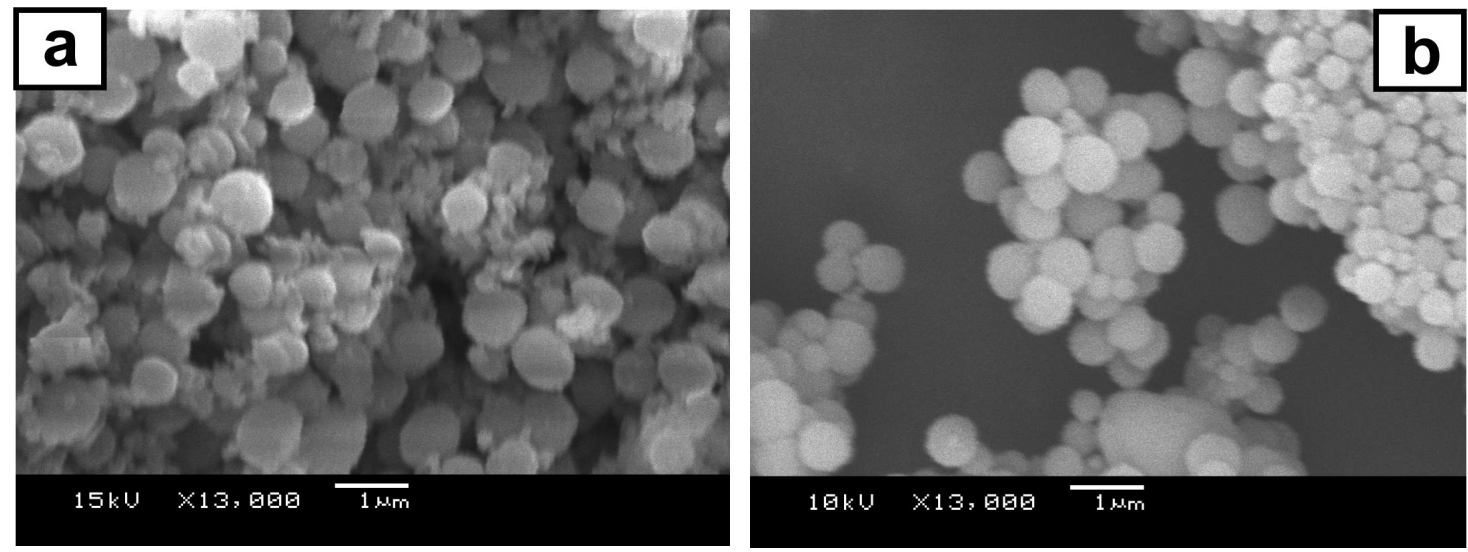

Figure 3. PSS @ $\mathrm{CaCO}_{3}$ particles prepared in the presence of $2.00 \mathrm{mg} \mathrm{mL}^{-1} \mathrm{PSS}$ and collected (a) immediately after the solution temperature reached $80{ }^{\circ} \mathrm{C}$ and (b) after $140 \mathrm{~min}$ at $80^{\circ} \mathrm{C}$.

area of this powder being at least two orders of magnitude higher, a feature that could prove attractive for applications in nanocomposite technology.

The formation of small particles (with a few micrometers down to the submicrometer range) has also been reported by Cölfen and Antonietti. ${ }^{3}$ In their study, the authors used a much more sophisticated polymer with a double hydrophilic block architecture, and bearing phosphonate groups, to attain crystal design control in the formation of microparticles by precipitation from concentrated calcium cation solutions, similarly to the work carried out in this study.

In the study reported herein, the decrease in the particle size from ca. 4 down to $0.8 \mu \mathrm{m}$ on increasing the polymer concentration is related to the extent of adsorption of the anionic polyelectrolyte onto the calcium planes. The surface coverage by adsorption increases with the polymer concentration, thus blocking sites essential for the incorporation of a new solute into the crystal lattice, which eventually reduces the crystal growth. ${ }^{38}$

Besides additives, such as homo- and block copolymers, the temperature can also play a significant role in the control of the calcium carbonate structure. ${ }^{7,20,39}$ We evaluated the effect of the temperature on the $\mathrm{CaCO}_{3}$ particle morphology after the addition of $\mathrm{CO}_{3}{ }^{2-}$ ions to the solution containing $\mathrm{Ca}^{2+}$ by raising the temperature from 25 to $80{ }^{\circ} \mathrm{C}$ with a

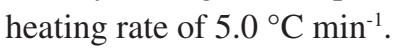

The SEM analysis of $\mathrm{CaCO}_{3}$ samples collected by crystallization from solutions containing PSS, after heating at $80^{\circ} \mathrm{C}$ (Figure 3a), revealed that several particles lost their initial spherical morphology. The particle morphology was clearly heterogeneous, in contrast to particles recovered from the synthesis medium at $25^{\circ} \mathrm{C}$ (Figure 1d). Indeed, the FTIR spectrum for the $\mathrm{CaCO}_{3}$ particles sampled from the solution immediately when the temperature reached $80^{\circ} \mathrm{C}$ exhibits a singular feature (Figure $4 \mathrm{a}$ ); the appearance of the lattice $\mathrm{H}_{2} \mathrm{O}$ libration or translation band at $580 \mathrm{~cm}^{-1}$ is indicative of the formation of a $\mathrm{CaCO}_{3} \cdot \mathrm{xH}_{2} \mathrm{O}$ hydrated phase. ${ }^{40}$ The water molecules are bound to the inorganic structure because the intensity of the characteristic band of free water molecules at ca. $3500 \mathrm{~cm}^{-1}$ does not correlate with the absorption intensity at $580 \mathrm{~cm}^{-1}$. Thermogravimetric analysis (Figure 5 and Table 1) confirmed a significant increase in the water content on raising the temperature of the crystallizing solution from $5 \%(\mathrm{~m} / \mathrm{m})$ at $25{ }^{\circ} \mathrm{C}$ to $14 \%(\mathrm{~m} / \mathrm{m})$ at $80{ }^{\circ} \mathrm{C}$. The difference in terms of water content can be readily seen from the first weight loss process, which is observed below $200{ }^{\circ} \mathrm{C}$.

The hydrated $\mathrm{CaCO}_{3}$ structure identified soon after increasing the temperature to $80^{\circ} \mathrm{C}$ is, however, not stable. The particles that had lost their spherical shape upon heating clearly recovered it when the reaction mixture was kept at $80^{\circ} \mathrm{C}$ for $140 \mathrm{~min}$. This transition is favored by the

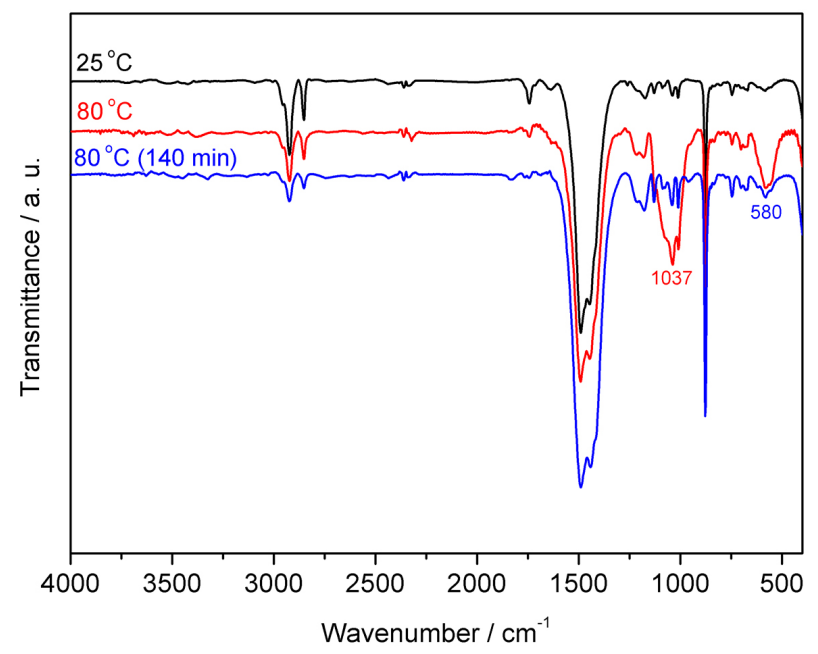

Figure 4. FTIR spectra of PSS@ $\mathrm{CaCO}_{3}$ particles prepared in the presence of $2.00 \mathrm{mg} \mathrm{mL}^{-1} \mathrm{PSS}$ and recovered at three different stages: immediately after the synthesis at $25^{\circ} \mathrm{C}$, when the solution temperature reached $80^{\circ} \mathrm{C}$, and after $140 \mathrm{~min}$ at $80^{\circ} \mathrm{C}$, as indicated. 


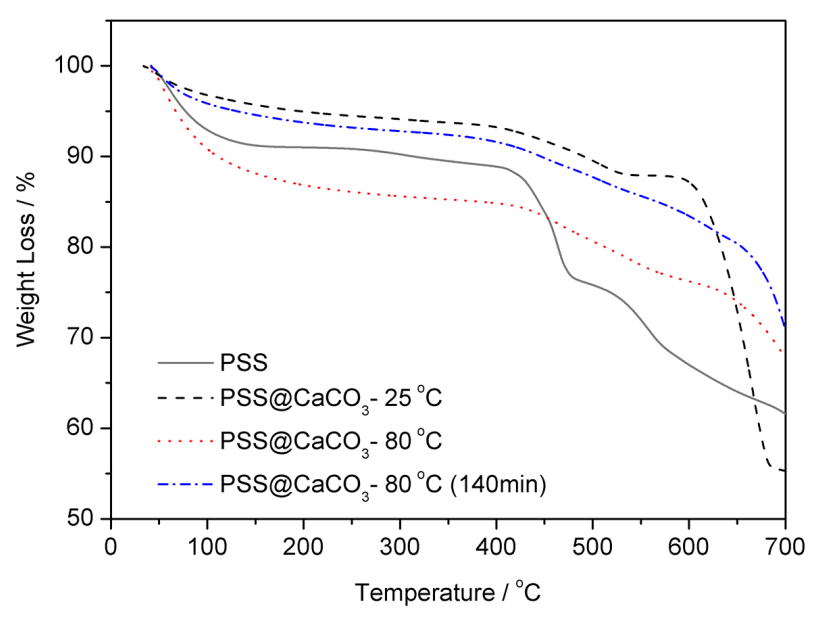

Figure 5. Thermogravimetric analysis of PSS polymer and PSS@ $\mathrm{CaCO}_{3}$ particles collected at three different stages during the synthesis: immediately after the synthesis at $25^{\circ} \mathrm{C}$, or when the solution temperature reached $80^{\circ} \mathrm{C}$, or after $140 \mathrm{~min}$ at $80^{\circ} \mathrm{C}$, as indicated.

poor stability of the crystalline $\mathrm{CaCO}_{3} \cdot \mathrm{xH}_{2} \mathrm{O}$ phases under ordinary conditions. ${ }^{41}$ This process is also accompanied by a decrease in the average particle diameter from 0.8 to $0.5 \mu \mathrm{m}$, as the results shown in Figure 3 reveal. These structural and morphological changes are due to the temperature only, as the material collected at $25^{\circ} \mathrm{C}$ either immediately after the addition of ammonium carbonate (standard protocol used in this study) or after $140 \mathrm{~min}$ were found to be the same.

The phase selection of calcium carbonate and the morphology of the resulting particles are strongly related to the interaction between the polymer and amorphous precursor developing particles, as the findings obtained in the presence of PAA and PS- $b$-PAA demonstrate. SEM imaging verified the formation of much larger polycrystalline spherical particles (Figure 6) when PSS was replaced by PAA under the same experimental conditions (i.e., at high $[\mathrm{Ca}]:[\mathrm{S}]$ ratio $(3: 1)$ with $[\mathrm{Ca}]=33 \mathrm{mmol} \mathrm{L}^{-1}$ and high polymer concentration).

The particles consisted predominantly of microspheres made of a collection of calcite polycrystallite aggregates (see Figure 6c), although the samples were somewhat heterogeneous at low polymer concentration (see Figures $6 \mathrm{a}$ and $6 \mathrm{~b}$ ). This observation is in agreement with the previously known stability of the calcite structure, with polycrystalline aggregates being more stable than regular microspheres under the specified conditions. ${ }^{5}$ The calcite structure was confirmed by the appearance of its typical FTIR absorption bands (see above) on the spectrum of a representative PAA@ $\mathrm{CaCO}_{3}$ sample shown in Figure 7a, as well as by the corresponding XRD pattern shown in Figure $7 b$.

Interestingly, we observed the presence of holes in almost all of the particles of the samples synthesized using PAA as a crystallizing solution modifier (see Figure 6). The formation of holes in calcite particles has been previously reported by Loges et al. ${ }^{19}$ In that study, however, particles were grown over self-assembled monolayers, and the formation of holes was attributed to the adhesion of particles to the surface and their subsequent movement from the original position, thus causing the outer surface to break. In our case, this series of events (i.e., adhesion to the surface followed by breaking away leaving a patch of material on the surface and a hole on the particle) is not present. Cai et al. ${ }^{9}$ reported the formation of hollow vaterite nanospheres from amorphous calcium carbonate solid particles, controlled by the presence of PSS and water.

Table 1. Results of thermogravimetric analysis of PSS polymer, $\mathrm{CaCO}_{3}$ precipitate, and $\mathrm{PSS} @ \mathrm{CaCO}_{3}$ particles

\begin{tabular}{|c|c|c|c|c|}
\hline Sample & $\mathrm{T}_{\mathrm{i}} /{ }^{\circ} \mathrm{C}$ & $\mathrm{T}_{\mathrm{f}} /{ }^{\circ} \mathrm{C}$ & Weight loss / \% & Weight loss related to \\
\hline \multirow{2}{*}{$\mathrm{CaCO}_{3}$} & 180 & 480 & 3 & $\mathrm{H}_{2} \mathrm{O}$ \\
\hline & 480 & 700 & 25 & $\mathrm{CaCO}_{3}$ \\
\hline \multirow{3}{*}{ PSS } & 25 & 145 & 9 & $\mathrm{H}_{2} \mathrm{O}$ \\
\hline & 220 & 480 & 15 & PSS \\
\hline & 480 & 700 & 15 & $\mathrm{CaCO}_{3}$ \\
\hline \multirow{3}{*}{ PSS@ $\mathrm{CaCO}_{3}-25^{\circ} \mathrm{C}$} & 25 & 220 & 5 & $\mathrm{H}_{2} \mathrm{O}$ \\
\hline & 375 & 559 & 6 & PSS \\
\hline & 559 & 700 & 33 & $\mathrm{CaCO}_{3}+\mathrm{PSS}$ \\
\hline \multirow{3}{*}{$\mathrm{PSS} @ \mathrm{CaCO}_{3}-80^{\circ} \mathrm{C}$} & 25 & 290 & 14 & $\mathrm{H}_{2} \mathrm{O}$ \\
\hline & 372 & 598 & 8 & PSS \\
\hline & 598 & 700 & 9 & $\mathrm{CaCO}_{3}+\mathrm{PSS}$ \\
\hline \multirow{3}{*}{ PSS@ $\mathrm{CaCO}_{3}-80^{\circ} \mathrm{C}-140 \mathrm{~min}$} & 25 & 214 & 7 & $\mathrm{H}_{2} \mathrm{O}$ \\
\hline & 338 & 547 & 7 & PSS \\
\hline & 547 & 700 & 10 & $\mathrm{CaCO}_{3}+\mathrm{PSS}$ \\
\hline
\end{tabular}



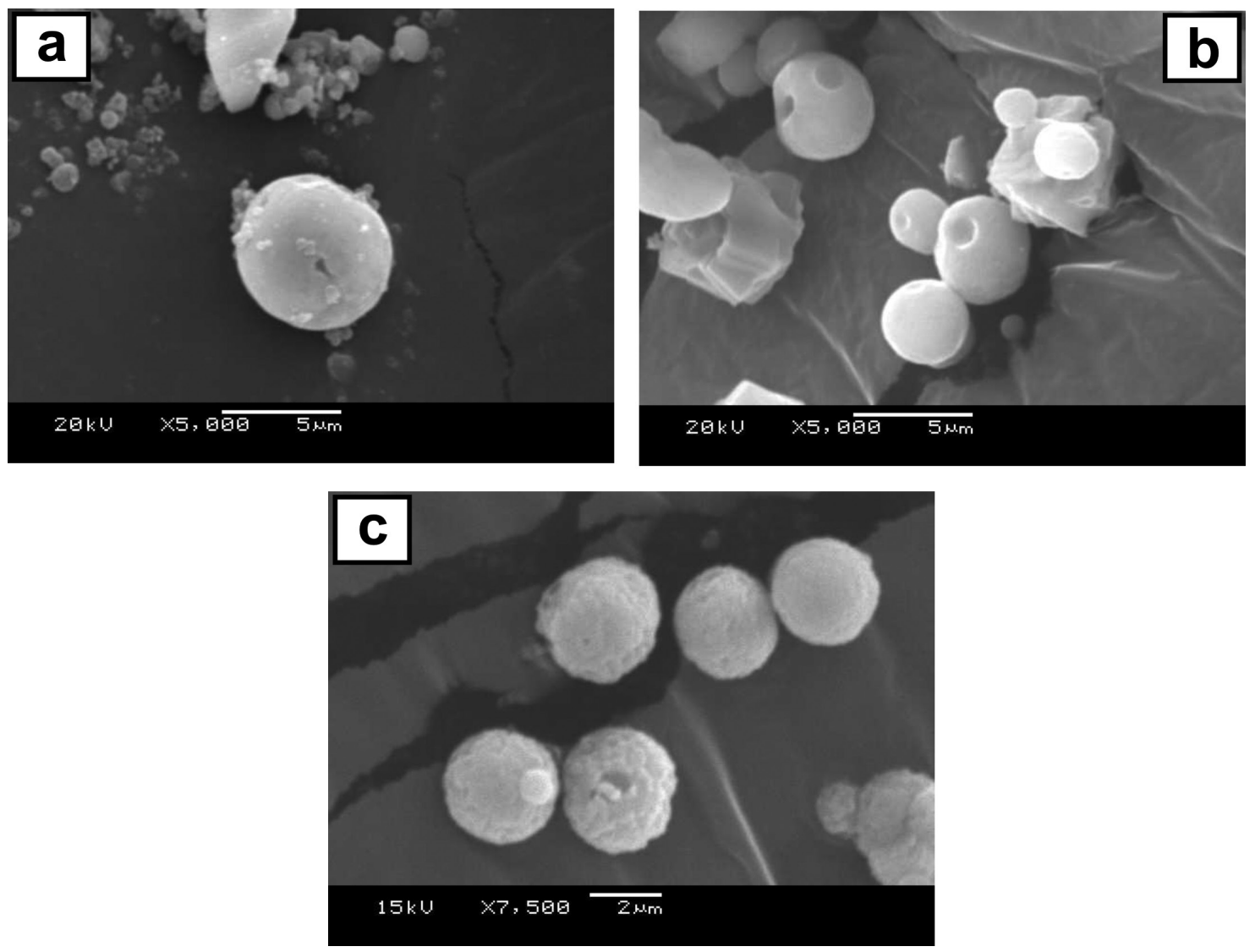

Figure 6. $\mathrm{PAA} @ \mathrm{CaCO}_{3}$ particles precipitated from solutions containing (a) 0.05 ; (b) 0.10 ; and (c) $2.00 \mathrm{mg} \mathrm{mL}^{-1}$ PAA.

On applying a much simpler experimental protocol than Cai et al., ${ }^{9}$ we did not observe holes in the vaterite particles prepared in the presence of PSS.

The holes evidenced in the present study in the presence of PAA are attributed to a combination of two effects: (i) local (i.e., at the hole formation site) redissolution of freshly precipitated calcium carbonate, and (ii) osmotic flow. The first effect is due to a local high concentration of PAA that develops inside the particles during precipitation. The dissociation of $\mathrm{Ca}^{\mathrm{II}} / \mathrm{PAA}$ complexes is one of the steps preceding the solid precipitation, and it generates a local increase in the PAA concentration (that is, the PAA is released to the medium and its concentration consequently increases). Under such conditions, freshly precipitated calcium carbonate can then be redissolved in a process governed by equilibrium displacement towards the formation of $\mathrm{Ca}^{\mathrm{II}} / \mathrm{PAA}$ complexes at certain points on the particles, eventually resulting in a hole, which will ultimately serve as a release valve for the high concentration of PAA inside the particle. ${ }^{9}$ This process is also favored by the osmotic pressure imbalance that evolves from a combination of osmotic flow and concentration changes. This is not observed in the presence of PSS because of its weaker interaction with $\mathrm{Ca}^{2+}$ cations as compared to PAA.
We also tested the hypothesis that the morphology of calcium carbonate particles can be controlled by letting $\mathrm{Ca}^{\mathrm{II}}$ interact with PAA segments in a volume featuring some degree of pre-organization. To this aim, a PS- $b$-PAA linear block copolymer system that self-assembled into core-shell spherical micelles of $25 \mathrm{~nm}$ diameter in aqueous solution was used. PAA constitutes the micellar shell, which is also where $\mathrm{Ca}^{\mathrm{II}}$ will preferentially be located given the favorable $\mathrm{Ca}^{\mathrm{II}} / \mathrm{PAA}$ interaction. In spite of such a strong change in the distribution of $\mathrm{Ca}^{\text {II }}$ ions in solution, the results revealed a rather poor control of the PS- $b$-PAA@ $\mathrm{CaCO}_{3}$ particle size and morphology. Large crystals with rhombohedral morphology were clearly abundant between the polydisperse spherical particles at any polymer concentration within the range of 0.01-2.0 mg mL-1 (see Figure 8). The FTIR analysis (Figure 7a) suggested that the samples are composed of calcite (typical IR absorption band at $714 \mathrm{~cm}^{-1}$ ) and vaterite (typical IR absorption band at $745 \mathrm{~cm}^{-1}$ ) phases in these samples. The XRD results (Figure 7b) confirmed the presence of calcite and vaterite phases.

The representative polymer@ $\mathrm{CaCO}_{3}$ particle systems described above were then used to prepare PCL-based composites, of which the rheological behavior was 
accessed by oscillatory rheology. Whilst the effective dispersion of particles in the polymer matrix still remains highly challenging, good particle dispersion at a concentration of $4 \%$ polymer@ $\mathrm{CaCO}_{3}$ in the PCL matrix
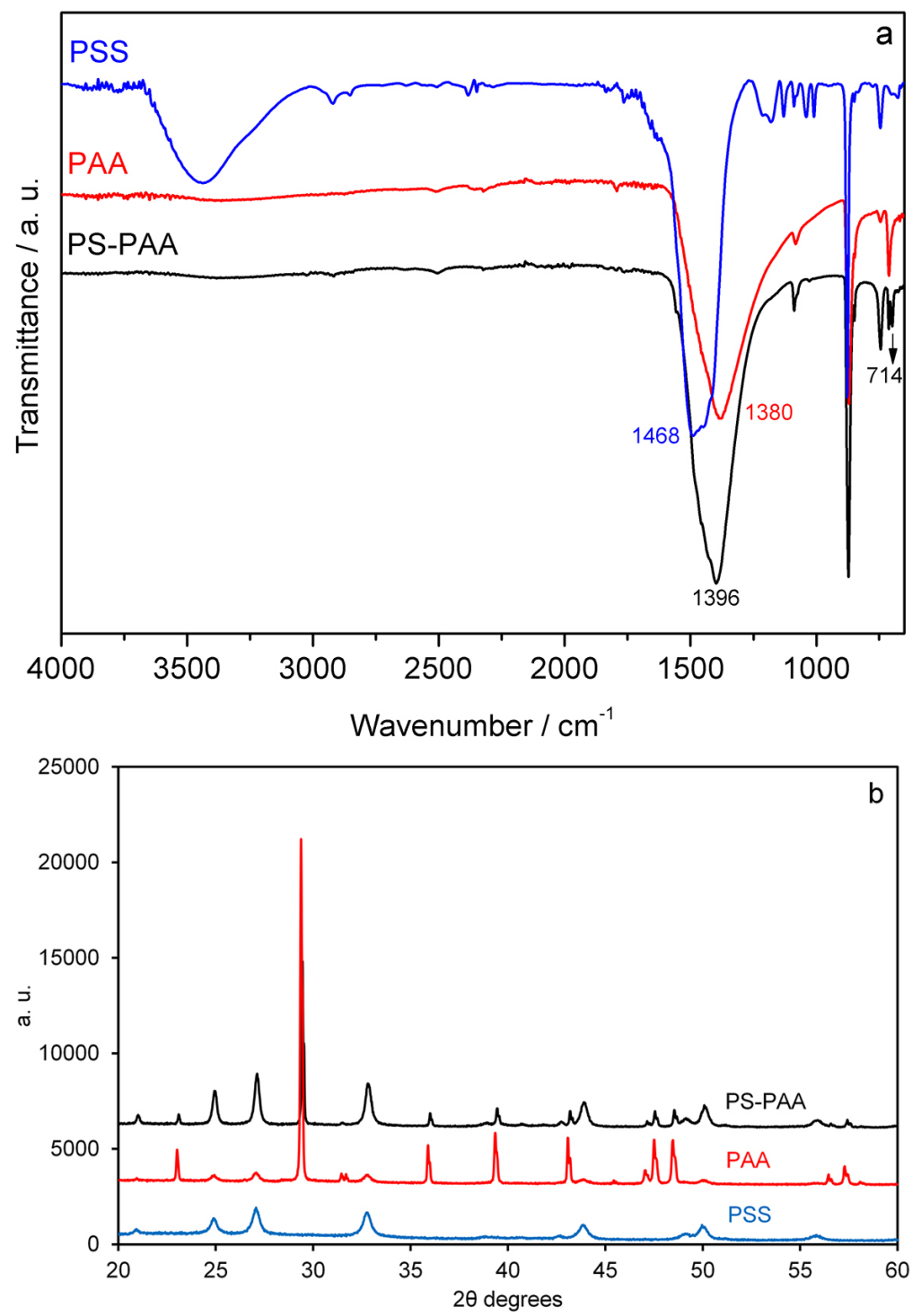

Figure 7. (a) FTIR spectra and (b) XRD patterns of polymer@ $\mathrm{CaCO}_{3}$ particles precipitated from crystallizing solutions containing either $0.10 \mathrm{mg} \mathrm{mL}^{-1}$ PSS, PAA or PS- $b$-PAA, as indicated.
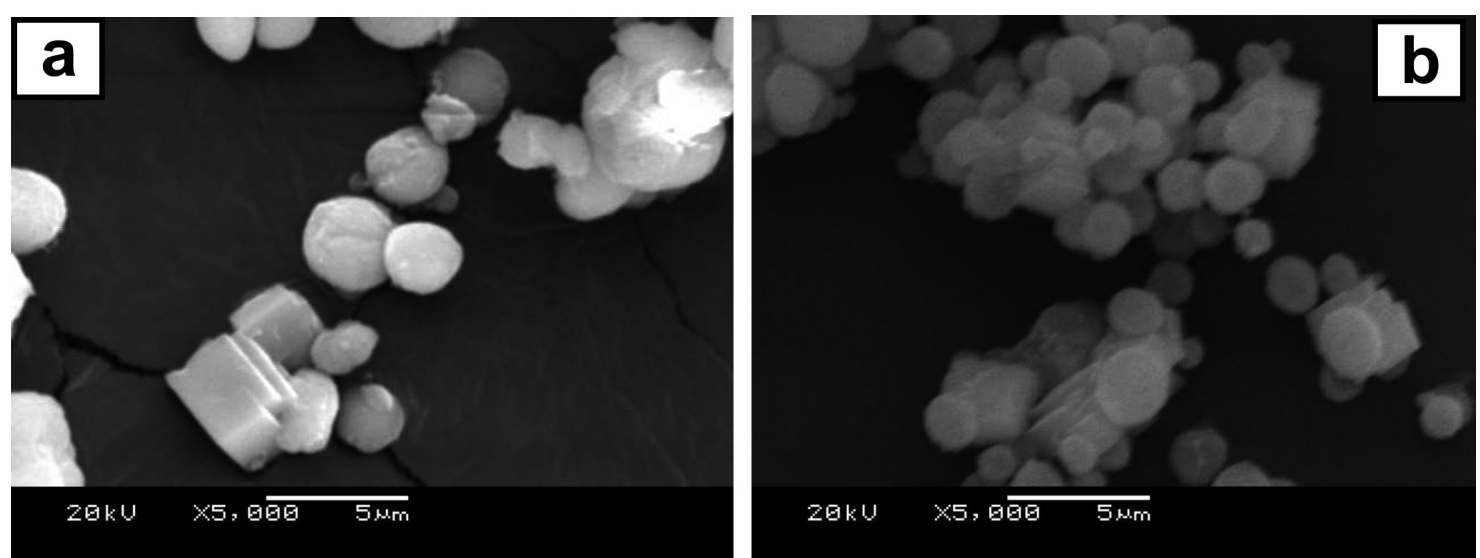

Figure 8. PS- $b$-PAA $@ \mathrm{CaCO}_{3}$ particles precipitated from solutions containing (a) 0.05 and (b) $0.10 \mathrm{mg} \mathrm{mL}^{-1} \mathrm{PS}-b$-PAA. 

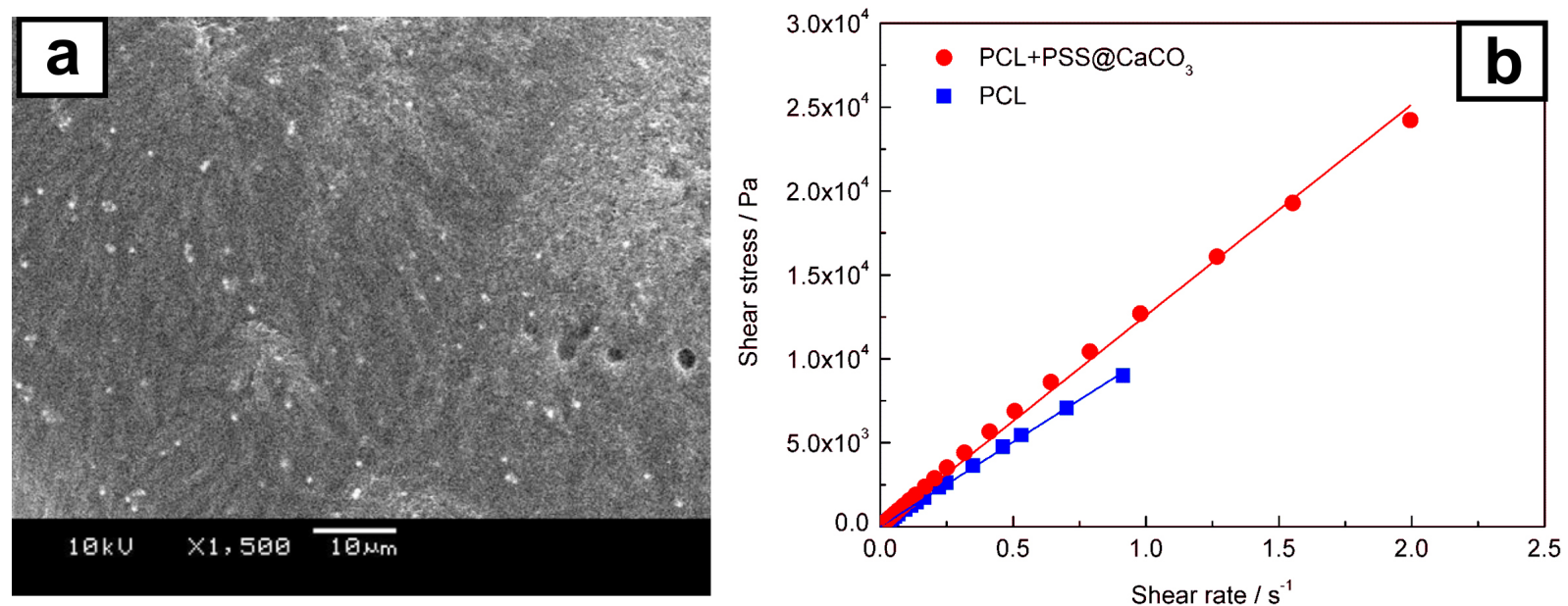

Figure 9. (a) SEM image of a PSS@ $\mathrm{CaCO}_{3} / \mathrm{PCL}$ composite (4\% PS@ $\mathrm{CaCO}_{3}$ ), and (b) corresponding relationship between shear stress and shear rate compared with neat PCL.

was evidenced by SEM imaging. This can be clearly seen in Figure 9a, which shows a typical SEM micrograph of the 4\% PSS@ $\mathrm{CaCO}_{3} / \mathrm{PCL}$ composite. Well-dispersed particles in this sample significantly improve the melt viscosity, that is, by approximately $30 \%$ (from 10.2 to $13.5 \mathrm{kPa} \mathrm{s}$ ).

\section{Conclusions}

A strong point of interest in relation to small calcium carbonate particles is the possibility of producing materials with a large surface area. Based on the results of this study, we conclude that submicrometer calcium carbonate particles can be synthesized from very simple inorganic salts, without the need to generate $\mathrm{CO}_{2}$ gas in situ, using homopolymers as the crystallization modifiers. This can be achieved in the presence of small amounts of the anionic homopolymer poly(sodium 4-styrenesulfonate) (PSS). The vaterite crystal phase of calcium carbonate is stabilized by PSS. Heating should be avoided to prevent broadening in the particle size distribution through a mechanism that involves the formation of an unstable phase.

We also observed that a pre-organized environment created by the selective distribution of $\mathrm{Ca}^{\mathrm{II}}$ ions in the shell of polystyrene- $b$-poly(acrylic acid) (PS- $b$-PAA) core-shell spherical micelles revealed rather poor control of the crystal growth size and morphology.

\section{Acknowledgments}

The authors acknowledge financial support from CNPq (Grant No. 475682/2012-2) and FAPERGS (Grant No. 12/2642-4). The authors are grateful to PhD Aleir A. F. de Paris for assistance with the SEM measurements and to the Núcleo de Química de Heterociclos (NUQUIMEUFSM) for the TGA measurements.

\section{References}

1. Osswald, T. A.; Menges, G.; Materials Science of Polymers for Engineers, $2^{\text {nd }}$ ed.; Hanser Publications: Kempten, Germany, 2003.

2. Butler, M. F.; Glaser, N.; Weaver, A. C.; Kirkland, M.; Heppenstall-Butler, M.; Cryst. Growth Des. 2006, 6, 781.

3. Cölfen, H.; Antonietti, M.; Langmuir 1998, 14, 582.

4. Donnet, M.; Aimable, A.; Lemaître, J.; Bowen, P.; J. Phys. Chem. B 2010, 114, 12058.

5. Kulak, A. N.; Iddon, P.; Li, Y.; Armes, S. P.; Cölfen, H.; Paris, O.; Wilson, R. M.; Meldrum, F. C.; J. Am. Chem. Soc. 2007, 129, 3729.

6. Naka, K.; Chujo, Y.; Chem. Mater. 2001, 13, 3245.

7. Babou-Kammoe, R.; Hamoudi, S.; Larachi, F.; Belkacemi, K.; Can. J. Chem. Eng. 2012, 90, 26.

8. Darder, M.; Aranda, P.; Ruiz-Hitzky, E.; Adv. Mater. 2007, 19, 1309.

9. Cai, A.; Xu, X.; Pan, H.; Tao, J.; Liu, R.; Tang, R.; Cho, K.; J. Phys. Chem. C 2008, 112, 11324.

10. Barhoum, A.; Van Lokeren, L.; Rahier, H.; Dufresne, A.; Van Assche, G.; J. Mater. Sci. 2015, 50, 7908.

11. Thenepalli, T.; Jun, A.; Han, C.; Ramakrishna, C.; Ahn, J.; Korean J. Chem. Eng. 2015, 32, 1009.

12. Gong, L.; Yin, B.; Li, L. P.; Yang, M. B.; Int. Polym. Process. 2015, 30, 217.

13. Zou, Z.; Bertinetti, L.; Politi, Y.; Jensen, A. C. S.; Weiner, S.; Addadi, L.; Fratzl, P.; Habraken, W. J. E. M.; Chem. Mater. 2015, 27, 4237.

14. Olderøy, M. Ø.; Xie, M.; Strand, B. L.; Draget, K. I.; Sikorski, P.; Andreassen, J.-P.; Cryst. Growth Des. 2011, 11, 520.

15. Barz, M.; Götze, S.; Loges, N.; Schüler, T.; Theato, P.; Tremel, W.; Zentel, R.; Eur. Polym. J. 2015, 69, 628.

16. Abebe, M.; Hedin, N.; Bacsik, Z.; Cryst. Growth Des. 2015 , 15,3609 . 
17. Cai, G.-B.; Zhao, G.-X.; Wang, X.-K.; Yu, S.-H.; J. Phys. Chem. C 2010, 114, 12948.

18. Guillemet, B.; Faatz, M.; Gröhn, F.; Wegner, G.; Gnanou, Y.; Langmuir 2006, 22, 1875.

19. Loges, N.; Graf, K.; Nasdala, L.; Tremel, W.; Langmuir 2006, 22, 3073.

20. Yu, J.; Lei, M.; Cheng, B.; Zhao, X.; J. Solid State Chem. 2004, $177,681$.

21. Yue, L.; Jin, D.; Shui, M.; Xu, Z.; Solid State Sci. 2004, 6, 1007.

22. Yue, L.; Zheng, Y.; Jin, D.; Microporous Mesoporous Mater. 2008, 113, 538 .

23. Yu, J. G.; Guo, H.; Davis, S. A.; Mann, S.; Adv. Func. Mater. 2006, 16, 2035.

24. Trushina, D. B.; Bukreeva, T. V.; Antipina, M. N.; Cryst. Growth Des. 2016, 16, 1311.

25. Cantaert, B.; Verch, A.; Kim, Y.-Y.; Ludwig, H.; Paunov, V. N.; Kröger, R.; Meldrum, F. C.; Chem. Mater. 2013, 25, 4994.

26. Lu, Y.; Mei, Y.; Schrinner, M.; Ballauff, M.; Möller, M. W.; Breu, J.; J. Phys. Chem. C 2007, 111, 7676.

27. Bastakoti, B. P.; Guragain, S.; Yokoyama, Y.; Yusa, S.-i.; Nakashima, K.; Langmuir 2011, 27, 379.

28. Huang, S.-C.; Naka, K.; Chujo, Y.; Langmuir 2007, 23, 12086.

29. Albertsson, A.-C.; Varma, I. K.; Biomacromolecules 2003, 4, 1466.

30. Labet, M.; Thielemans, W.; Chem. Soc. Rev. 2009, 38, 3484.
31. Liu, H.; Han, C.; Dong, L.; Polym. Compos. 2010, 31, 1653.

32. Liang, J.-Z.; Zhou, L.; Tang, C.-Y.; Tsui, C.-P.; J. Appl. Polym. Sci. 2013, 128, 2940.

33. Tuba, F.; Oláh, L.; Nagy, P.; J. Appl. Polym. Sci. 2011, 120, 2587.

34. Du, W.; Nyström, A. M.; Zhang, L.; Powell, K. T.; Li, Y.; Cheng, C.; Wickline, S. A.; Wooley, K. L.; Biomacromolecules 2008, 9, 2826.

35. Adler, H. H.; Kerr, P. F.; Am. Mineral. 1963, 48, 839.

36. Vagenas, N. V.; Gatsouli, A.; Kontoyannis, C. G.; Talanta 2003, $59,831$.

37. Shui, M.; Yue, L.; Xu, Z.; Spectrochim. Acta, Part A 2004, 60, 441.

38. Yang, M.; Jin, X.; Huang, Q.; Colloids Surf. A 2011, 374, 102.

39. Vucak, M.; Pons, M. N.; Peric, J.; Vivier, H.; Powder Technol. 1998, $97,1$.

40. Tlili, M. M.; Amor, M. B.; Gabrielli, C.; Joiret, S.; Maurin, G.; Rousseau, P.; J. Raman Spectrosc. 2002, 33, 10.

41. Brečević, L.; Nielsen, A. E.; J. Cryst. Growth 1989, $98,504$.

Submitted: February 18, 2016

Published online: June 30, 2016

FAPERGS/CAPES has sponsored the publication of this article. 